\title{
Akut gastrointestinal sistem kanması: Endoskopi sonrası sırada ne var? Olgu sunumu
}

\author{
Acute gastrointestinal bleeding: What is the next step after endoscopy? A case report
}

\author{
(D) Feyzi BOSTAN ${ }^{1}$, (D) Halit KAYA ${ }^{1}$, (DErsin KAPAĞAN ${ }^{1}$, (D) Rıdvan YAVUZ², (D) Ayhan Hilmi ÇEKIN³ \\ Sağlık Bilimleri Antalya Eğitim ve Araştırma Hastanesi ${ }^{1}$ Dahiliye Kliniği, ${ }^{2}$ Gastroenteroloji Cerrahisi Kliniği, ${ }^{3}$ Gastroenteroloji Kliniği, \\ Antalya
}

\begin{abstract}
Gastrointestinal sistem kanamalarının nadir sebepleri arasında gastrointestinal stromal tümörler vardır. Bu tümörler, gastrointestinal sistemin en sık görülen mezenkimal neoplazmlarıdır. Ince barsak yerleşimli olduklarında üst gastrointestinal sistem endoskopide ve kolonoskopide saptanması güç olabilir. Ince barsak yerleşimli bu tümörleri saptamak için çeşitli non-invaziv ve invaziv görüntüleme yöntemleri kullanılır. Bu yöntemlerden biri de manyetik rezonans enterografidir. Bu yazımızda acil servise melena şikayetiyle gelen 62 yaşında erkek hastamızı sunuyoruz. Endoskopik görüntülemelerde ve eritrosit işaretli sintigrafide kanama odağı ve kanamaya sebep olan patolojinin saptanamaması üzerine yapılan manyetik rezonans enterografide jejunum-ileum bileşkesinde yumuşak doku intensitesinde kitleye rastlandı. Operasyonla çıkarılan kitlenin patolojisi gastrointestinal stromal tümör olarak geldi. Operasyon sonrası hasta şifa ile taburcu edildi. Gastrointestinal sistem kanamalarında tanı ve tedavide endoskopik yöntemler ilk başvurulan araçlardır. Endoskopik işlemlerin yetersiz kaldığı durumlarda invasiv araçlara başvurulabilir. Bu araçlara başvurmadan, endoskopik yöntemlerle nedeni saptanamayan gastrointestinal sistem kanamalarda non-invasiv bir yöntem olan manyetik rezonans enterografi akla gelmelidir.
\end{abstract}

Anahtar kelimeler: Gastrointestinal stromal tümör, manyetik rezonans enterografi, gastrointestinal sistem kanaması

\section{GíRiş}

Gastrointestinal sistem (GiS) kanamalarının kaynaklandığı yere bağlı olarak benign ve malign bir çok nedeni vardır. Bu nedenler arasında özofajit, peptik ülserler, inflamatuvar bağırsak hastalığı, vasküler ektaziler, portal hipertansif gastropati, ince bağırsak tümörleri, kolon kanserleri, divertiküler hastalıklar, ilaçlar, enfeksiyöz ajanlar ve iskemik olaylar bulunmaktadır (1). İnce barsak kaynaklı kanama, Gis kanama ile başvuran tüm hastaların \%5-10'unu oluşturur (2). Gastrointestinal stromal tümörler (GIST) gastrointestinal sistemin en yaygın mezenkimal neoplazmalardır (3). Görülme sıklığı sırasıyla mide (\%40-70), ince barsaklar (\%20-40), kolon ve rektum (\%5-15), omentum/ mezenter (\%7) ve özofagusdur (<\%5). Bu lezyonların en

Iletişim: Feyzi BOSTAN

Sağlık Bilimleri Üniversitesi, Antalya Eğitim ve Araştırma Hastanesi Dahiliye Kliniği, Varlık Mah., Muratpaşa, Antalya

Tel: +90242 24940 00-3420•E-mail: feyzi@dr.com
Gastrointestinal stromal tumors are among the rare causes of gastrointestinal system bleeding. These tumors are the most common mesenchymal neoplasms of the gastrointestinal tract. When located in the small intestine, they may be difficult to detect by upper gastrointestinal endoscopy and colonoscopy. Various non-invasive and invasive imaging techniques have been employed to detect these small bowel tumors. One of these methods includes magnetic resonance enterography. In this study, we have presented a 62-year-old male patient who was admitted to the emergency department with the complaint of melena. Because no causative factor for bleeding was detected by endoscopic imaging and erythrocyte-labeled scintigraphy, magnetic resonance enterography was performed. A mass of soft tissue density was detected at the jejunum-ileum junction. The pathology of the surgically removed mass was gastrointestinal stromal tumor. After the operation, the patient was discharged with full recovery. Endoscopic methods are the first-line methods in diagnosis and treatment of gastrointestinal system bleeding. In cases where endoscopic procedures are insufficient, non-invasive tools can be used. Magnetic resonance enterography, which is a non-invasive method, should therefore be considered in gastrointestinal system bleedings when the source of bleeding cannot be detected by endoscopic methods.

Key words: Gastrointestinal stromal tumor, magnetic resonance en terography, gastrointestinal system bleeding

sık klinik bulgusu kanamadır (4). İnce barsak yerleşimli lezyonların teşhisi zordur çünkü rutin endoskopiyle erişilmesi güç olma eğilimindedirler. İnce barsak lezyonlarının teşhisi için ince barsak baryum çalışmaları, bilgisayarlı tomografi (BT) anjiyografi, video kapsül endoskopi gibi çeşitli sensivite ve spesifiteye sahip tanısal yöntemler mevcuttur (5).

Biz bu yazımızda üst GiS endoskopi ve kolonoskopi ile kanama odağı saptanamayan ve manyetik rezonans (MR) enterografi ile ince barsak görüntülemesi sonrası jejunum-ileum bileşkesinde 52×36 mm lezyon saptanan, operasyon sonrası patolojik tanısı GIST gelen 62 yaşında erkek hastamızdan bahsedeceğiz.

Bostan F, Kaya H, Kapağan E, et al. Acute gastrointestinal bleeding: What is the next step after endoscopy? A case report. The Turkish Journal of Academic Gastroenterology 2020;19:156-158. DOI: 10.17941/agd.845274

Geliş Tarihi: 24.11.2020 • Kabul Tarihi: 08.12.2020 

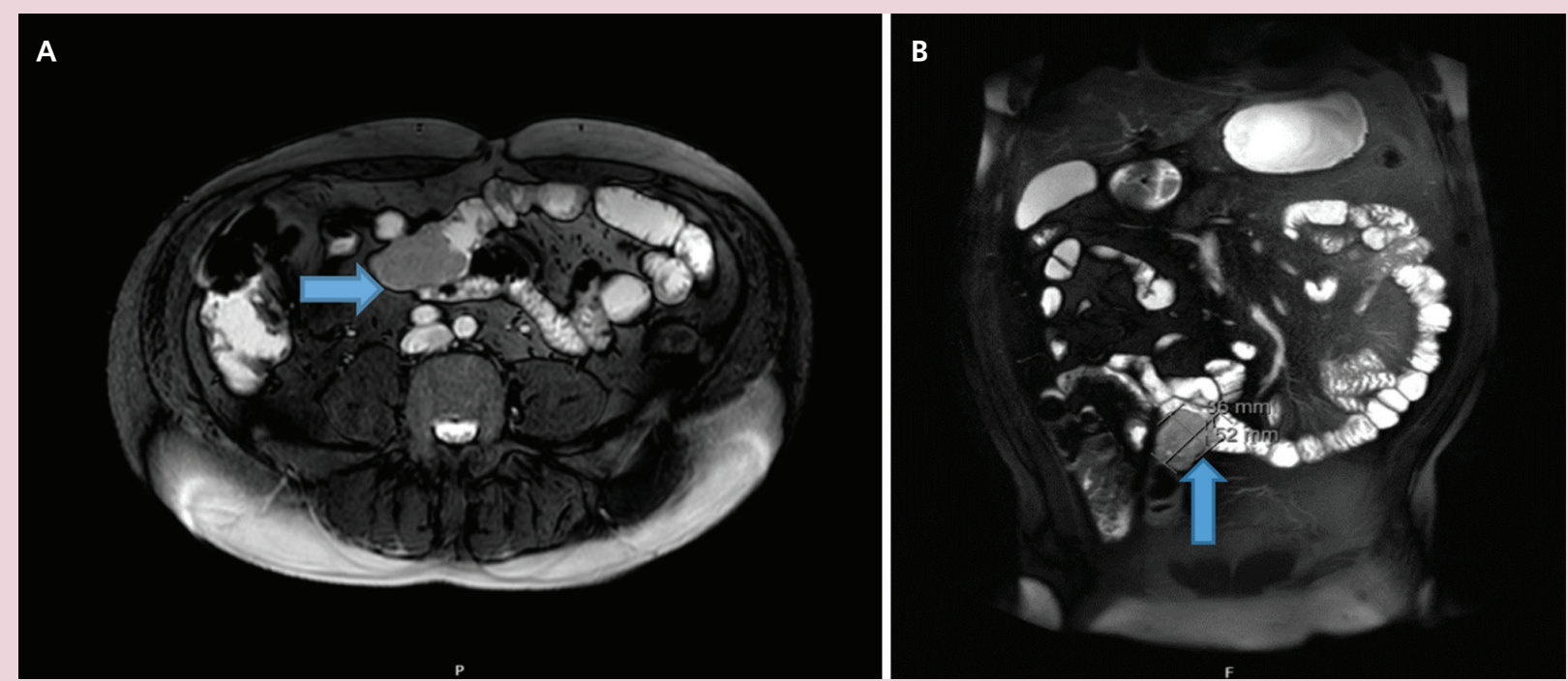

Resim 1. MR enterografi görüntüleri. (A) Yatay kesit, (B) Koronal kesit. Jejunum-ileum bileşkesinde $52 \times 36$ mm boyutlarında yumuşak doku intensitesinde kitle (mavi oklarla belirtilmiştir).

\section{OLGU SUNUMU}

Bilinen ek hastalığı olmayan 62 yaşında erkek hasta iki gün boyunca devam eden siyah renkli, cıvık kıvamda dışkılama ve iki defa presenkop şikayeti ile acil servise başvurdu. Yapılan fizik muayenede tansiyon: 115/75 mmHg, nabı: $85 / d k$, vücut Isısı: $36.5^{\circ} \mathrm{C}, \mathrm{O}_{2}$ satürasyonu $\% 98$, solunum sayısı 15/dk idi. Barsak sesleri hiperaktif ve rektal tuşede melena dışında pozitif bulgusu yoktu. Hastanın tam kan sayımında hemoglobin ( $\mathrm{Hb}$ ): $8.8 \mathrm{~g} / \mathrm{dL}$ idi. Aktif kanama olduğu düşünülen hasta acil üst gastrointestinal endoskopiye alındı. Endoskopide grade A-B özofajit ve eroziv gastrit dışında bulgu saptanmadı. Takiplerinde 6 ünite eritrosit süspansiyonu ihtiyacı olacak kadar kanamaya devam eden hastaya kolonoskopi yapıldı. Kolonoskopide kolon normaldi ve terminal ileumda $30 \mathrm{~cm}$ kadar ilerlendi. Yukarıdan melena şeklinde kanama görüldü. Eritrosit işaretli sintigrafi yapılan hastada kanama odağı gösterilemedi. Bunun üzerine MR enterografi çekildi. MR enterografide jejunumileum bileşkesinde 52×36 mm boyutlarında yumuşak doku intensitesinde kitle saptandı (Resim 1). Cerrahi tarafından laparoskopik jejunal rezeksiyon ve anastomoz yapıldı. Operasyon materyalinin patolojisi yüksek dereceli ülserleşmiş GIST olarak geldi. Operasyon sonrası kanama açısından stabil olan hasta taburcu edildi. Vaka sunumu için hastadan bilgilendirilmiş onam formu imzalatılarak onam alındı.

\section{TARTIŞMA}

Sebebi bilinmeyen gastrointestinal kanama özofagogastroduodenoskopi ve kolonoskopi gibi klasik yöntemlerle tespit edilemeyen ve tekrarlayan demir eksikliği anemi- si veya tekrarlayan hematemez, melena şeklinde ortaya çıkan kanamalar şeklinde tanımlanır (6). İnce barsak tümörleri, sebebi bilinmeyen gastrointestinal kanamanın nedenlerinin \%5-10'unu oluşturur. GIST barsak duvarında gastrointestinal pacemaker hücreleri olan interstisyel Cajal hücrelerinden köken alır. GIST'ler en çok midede (\%40-60) ve jejunum/ileumda (\%25-30) görülür (7). Bu tümörler GiS' deki lokalizasyonlarına göre semptom ve klinik bulgu gösterirler (8). En sık görülen prezentasyon şekli, melena veya hematemez şeklinde olabilen bariz veya belirti göstermeyen gizli gastrointestinal kanamadır (9).

Sebebi bilinmeyen gastrointestinal kanamalarda tanıya ulaşmada klinik belirtilere, tanısal şüpheye veya diğer diagnostik çalışmalarda tanıya ulaşılmasına bağlı olarak

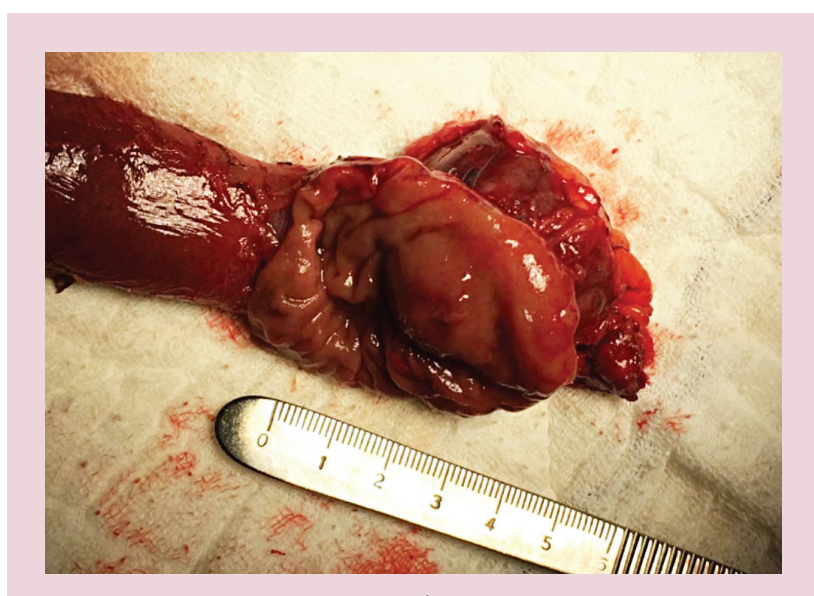

Resim 2. Operasyon materyali 
farklı duyarlıık ve özgüllükte birçok seçenek vardır. Amerikan Gastrointestinal Endoskopi Derneği, sebebi bilinmeyen gastrointestinal kanamaların tespiti için ilk etapta üst Gis endoskopi ve/veya kolonoskopi ve sonuçlar negatifse kapsül endoskopi, BT anjiyografi, BT veya manyetik rezonans (MR) enterografiyi öneren bir teşhis algoritması önermektedir (10). Son yıllarda BT ve MR cihazlarının teknolojik olarak gelişmesi ince barsak tanısal çalışmalarına yenilikçi bir yaklaşım getirmiştir. Bu tekniklerin klinik pratikte sensitiviteleri \%50'dir $(11,12)$.

MR enterografide çoğu protokol, prosedürden önce en az 4 ile 6 saat açlık gerektirir. MR odasında inceleme 25 ile 30 dakika sürer ve radyoloji bölümündeki hazırlık dahil tüm çalışma yaklaşık 90 dakika sürer (13). Tetkik öncesi motiliteye bağlı artefaktları azaltmak ve lümen distansiyonunu artırmak amacıyla tam barsak temizliği ve antikolinerjik ajanların uygulanması önerilmektedir (14). Oral kontrast uygulamasının hacmi ve görüntüleme zamanlaması arasında farklı uygulamalar olsa da hastaya görüntülemeden $40 \mathrm{dk}$ önce 1 litre kontrast madde içirilen protokolün hem hasta uyumu hem de $\mathrm{MR}^{\prime}$ da zamanın verimli kullanımı açısından etkili olduğunu düşünülmektedir (15). MR enterografi için kullanılan optimal görüntüleme protokolü konusunda fikir birliği yoktur. Çeşitli sekanslarda 1.5-Tesla MR görüntüleme işlemi gerçekleştirilir (13).

İnce barsak değerlendirmeleri için MR görüntülemenin bilgisayarlı tomografiye göre avantajları arasında üstün

\section{KAYNAKLAR}

1. Kim BS, Li BT, Engel A, et al. Diagnosis of gastrointestinal bleeding: A practical guide for clinicians. World J Gastrointest Pathophysiol 2014;5:467-78.

2. Pennazio M, Spada C, Eliakim R, at al. Small-bowel capsule endoscopy and device-assisted enteroscopy for diagnosis and treatment of small-bowel disorders: European Society of Gastrointestinal Endoscopy (ESGE) Clinical Guideline. Endoscopy 2015;47:352-76.

3. Miettinen M, Lasota J. Gastrointestinal stromal tumors--definition, clinical, histological, immunohistochemical, and molecular genetic features and differential diagnosis. Virchows Arch 2001;438:1-12.

4. Miettinen M, Sobin LH, Lasota J. Gastrointestinal stromal tumors of the stomach: a clinicopathologic, immunohistochemical, and molecular genetic study of 1765 cases with long-term follow-up. Am J Surg Pathol 2005;29:52-68.

5. Rockey DC. Occult gastrointestinal bleeding. Gastroenterol Clin North Am 2005;34:699-718.

6. Concha R, Amaro R, Barkin JS. Obscure gastrointestinal bleeding, diagnostic and therapeutic approach. J Clin Gastroenterol 2007;41:242-51.

7. Fletcher CD, Berman JJ, Corless C, et al. Diagnosis of gastrointestinal stromal tumors: A consensus approach. Hum Pathol 2002;33:459-65.

8. Miettinen M, Sobin LH, Lasota J. Gastrointestinal stromal tumors of the stomach: a clinicopathologic, immunohistochemical, and molecular genetic study of 1765 cases with long-term follow-up. Am J Surg Pathol 2005;29:52-68. kontrast çözünürlüğü, iyonlaştırıcı radyasyon maruziyetinin olmaması, çok düzlemli birincil görüntü veri kümelerini elde etme yeteneği, uzun bir çekim süresi boyunca sıralı görüntü serileri elde etme yeteneği, çok fazlı görüntüleme yeteneği ve daha iyi güvenlik profilleri ile intravenöz kontrast madde kullanımı sıralanabilir. MR enterografi ayrıca ek miktarda oral kontrast madde uygulandıktan sonra farklı aralıklarla dizileri tekrarlayarak ince bağırsak peristaltizmi ve lümenin daraldığı alanların ve lümen içi kitlelerin uzatılabilirliğinin dinamik değerlendirmelerine izin verir (16).

Çift balonlu enteroskopi hem nedeni saptanamayan Gis kanamalarında hem de başka sebeple ince barsağın endoskopik olarak değerlendirilmesine imkan tanıyan çok yararlı bir metottur. Bizim hastanemizde de yapılabiliyor olsaydı MR enterografiden önce çift balonlu enteroskopi yapılabilirdi.

Gastrointestinal sistem kanamalarında tanı ve tedavide endoskopik yöntemler ilk başvurulan araçlardır. Endoskopik işlemlerin yetersiz kaldığı durumlarda invasiv araçlara başvurulabilir. Bu araçlara başvurmadan, endoskopik yöntemlerle nedeni saptanamayan gastrointestinal sistem kanamalarında non-invasiv bir yöntem olan manyetik rezonans enterografi akla gelmelidir.

\section{Bu vaka sunumumuzda Helsinki deklarasyonuna uyulmuştur. Herhangi bir çıkar çatışması ve finansal katkı yoktur.}

9. Heinrich MC, Corless CL. Gastric GI stromal tumors (GISTs): the role of surgery in the era of targeted therapy J Surg Oncol 2005;90:195207; discussion 207.

10. Rondonotti E, Marmo R, Petracchini M, de Franchis R, Pennazio M. The American Society for Gastrointestinal Endoscopy (ASGE) diagnostic algorithm for obscure gastrointestinal bleeding: eight burning questions from everyday clinical practice. Dig Liver Dis 2013;45:179-85.

11. Horsthuis K, Bipat S, Bennink RJ, et al. Inflammatory bowel disease diagnosed with US, MR, scintigraphy, and CT: meta-analysis of prospective studies. Radiology 2008;247:64-79.

12. Lee SS, Oh TS, Kim HJ, et al. Obscure gastrointestinal bleeding: diagnostic performance of multidetector CT enterography. Radiology 2011;259:739-48.

13. Costa-Silva L, Brandão AC. MR enterography for the assessment of small bowel diseases. Magn Reson Imaging Clin N Am 2013;21:365-83.

14. Miao F, Wang M-L, Tang Y-H. New progress in CT and MRI examination and diagnosis of small intestinal tumors. World J Gastrointest Oncol 2010;2:222-8.

15. Tolan DJ, Greenhalgh R, Zealley IA, Halligan S, Taylor SA. MR enterographic manifestations of small bowel Crohn disease. Radiographics 2010;30:367-84.

16. Amzallag-Bellenger $E$, Oudjit A, Ruiz A, et al. Effectiveness of MR enterography for the assessment of small-bowel diseases beyond Crohn disease. Radiographics 2012;32:1423-44. 